\title{
О ГЛЯЦИОТЕКТОНИЧЕСКОЙ ПЕРЕРАБОТКЕ МЕЖЛЕДНИКОВЫХ ОТЛОЖЕНИЙ В РАЗРЕЗАХ КАРУКЮЛА И КЫРВЕКЮЛА (ЭСТОНИЯ)
}

При исследованиях в области древнематерикового оледенения за основу расчленения толщ преимущественно принимается положение в разрезе торфяников и других межледниковых образований. Работы последних лет показывают, что четвертичные и даже более древние породы нередко претерпевали заметную гляциотектоническую переработку. В результате этого межледниковые слои, содержащие ископаемые органические остатки, на многих участках сильно дислоцированы, собраны в складчато-чешуйчатые пакеты и включены в виде отторженцев в ледниковую толщу. При этом более древние. отложения расположены иногда в разрезе выше, чем молодые. Все это привело к ненадежности принятых стратиграфических построений.

Вместе с тем проблемы «отторженцевой» стратиграфии, базирующейся на учете гляцигенно перемещенных или дислоцированных толщ, почти не анализнровались. До сих пор не выявлены признаки, указывающие на аллохтонность или автохтонность межледниковых интервалов. С названными явлениями одними из первых в СССР столкнулись геологи Эстонии. При детальном изучении ряда разрезов (Карукюла, Кырвекюла) ими был получен богатый фактический материал, позволяющий решить вопрос о наличии происхождения здесь гляцигенной переработки.

Не многие межледниковые образования плейстоцена Восточно-Европейской равнины подвергались такому подробному исследованию, как разрез Карукюла, расположенный на юго-западе Эстонии. Первые сведения приведены К. К. Орвику еще в 1941 году. Им же, а позже сотрудниками Института геологии АН ЭССР и Управления геологии ЭССР заложены в Карукюла 43 скважины ручного, 12 скважин вибрационного, 2 скважины роторного бурения и 12 шурфов, которые позволяют с достаточной уверенностью проследить за условиями залегания озерноболотных межледниковых отложений в этом местонахождении (Орвику, Пиррус, 1965; Каяк и др., 1970; Раукас, 1978; Лийвранд, 1979).

Лихвинская (гольштейнская) межледниковая толща в Карукюла залегает в глубокой ледниковой ложбине, врезанной в среднедевонские и нижнесилурийские породы на глубину около 200 м. Днище ложбины проникает до минусовых отметок 142-110 м. Она вытянута в восток-северо-восточном направлении и фрагментами прослеживается на расстоянии примерно 60 км. В пределах этого переуглубления по соседству с разрезом Карукюла суммарная мощность четвертичных образований достигает 207 м, тогда как непосредственно на рассматриваемом участке, у юго-восточного борта ложбины мощность сокращается до 37,7 м (скв. 182). Еще меньшие значения (до 10 м) установлены на плечах вреза.

Ложбина у д. Карукюла заполнена разновозрастными моренами, озерно-ледниковыми алевритами и глинами, флювиогляциальными песками и гравием, озерными отложениями (алевриты), а также органоген- 
ными образованиями. Перекрывающая эту толщу морена последнего оледенения имеет красно-бурую окраску, залегающие ниже - серую или коричневую. На поверхности погребенная ложбина отчетливого выражения не имеет. Здесь в основном распространены формы друмлиноподобного и озерно-ледникового рельефа.

Такие же по возрасту межледниковые отложения установлены и в разрезе Кырвекюла, который расположен 5 км северо-восточнее Тарту, непосредственно у юго-западной окраины Саадъярвского друмлинового поля (Лийвранд, Саарсе, 1983). В этом месте озерно-болотные слои вскрыты бурением в основном под мореной последнего оледенения (мощность $2-3$ м) на глубине около $3-5$ м. Межледниковая толща включена в песчаные отложения, имеет довольно сложное строение и приурочена к древней погребенной долине, врезанной на глубину 28 м в среднедевонские породы. Мощность четвертичных отложений в переуглублении на данном участке достигает $20-23$ м, составляя до нескольких метров на его плечах. Погребенная долина фрагментами выражается в рельефе современной поверхности.

В связи с важным стратиграфическим значением описанных разрезов возникла потребность в детальном анализе условий залегания (автохтонности или аллохтонности) межледниковых образований. Анализ имеющихся данных показывает, что в том и другом разрезах органогенная толща претерпела заметное гляциотектоническое воздействие и находится во вторичном залегании (рис. 1-3). Об этом свидетельствуют прежде всего следующие факты.

1. Межледниковые толщи, элементы залегания которых прослеживаются с помощью довольно густой сети выработок, в пределах переуглублений правильно простирающихся и выклинивающихся к периферии линз не образуют; они прерывисты, фрагментарны и слагают плохо увязывающиеся между собой блоки пород. Слои в этих блоках преимущественно наклонены в проксимальном направлении, при этом восстают на коротких расстояниях в дистальную сторону от нескольких до $10-11^{\circ}$, что отличает вовлеченные в гляцигенное перемещение породы ледникового субстрата. Характерны формы в виде пластин (чешуй), которые в продольном сечении наклонены в сторону ледникового напоpa, а в поперечном имеют параллельно-горизонтальное или ложкообразное строение. Окончания пластин круто обрываются без уменьшения мощности слоев. У нормально развитых голоценовых торфяников, как правило, таких явлений не наблюдается.

2. В толще самих межледниковых аккумуляций нарушена стратификация слоев. Так, в скв. 2 разреза Кырвекюла (рис. 3) отложения, соответствующие пыльцевым зонам I и II, дважды появляются в разрезе (сдвоение интервалов), причем у нижнего интервала отсутствует основание (подзона I $a$ и $\mathrm{I} b$ ). Такое истачивание часто наблюдается в подошве пластин пород, которые претерпели горизонтальное смещение. Сходное явление отмечается и в скв. 1, 2 и 182 разреза Карукюла.

3. В разрезе Кырвекюла в месте довольно крутого наклона описываемых пород, где на отрезке в 36 м отложения погружаются более чем на 2 м, толщина прослоев, соответствующих одним и тем же пыльцевым зонам, остается одинаковой, выдержанной, а контакты наслоений параллельны, без признаков выклинивания материала. В условиях современного осадконакопления в подобной ситуации практически всегда регистрируются фациальные изменения в характере отложений. Это позволяет сделать вывод, что наклон слоев - постседиментационное явление.

4. В озерно-болотных отложениях разреза Карукюла наименьшей выдержанностью отличается слой в его основании. Часто на коротких расстояниях (менее 10 м) резко изменяется мощность пород, вследствие чего поверхность субстрата зубчатая. 


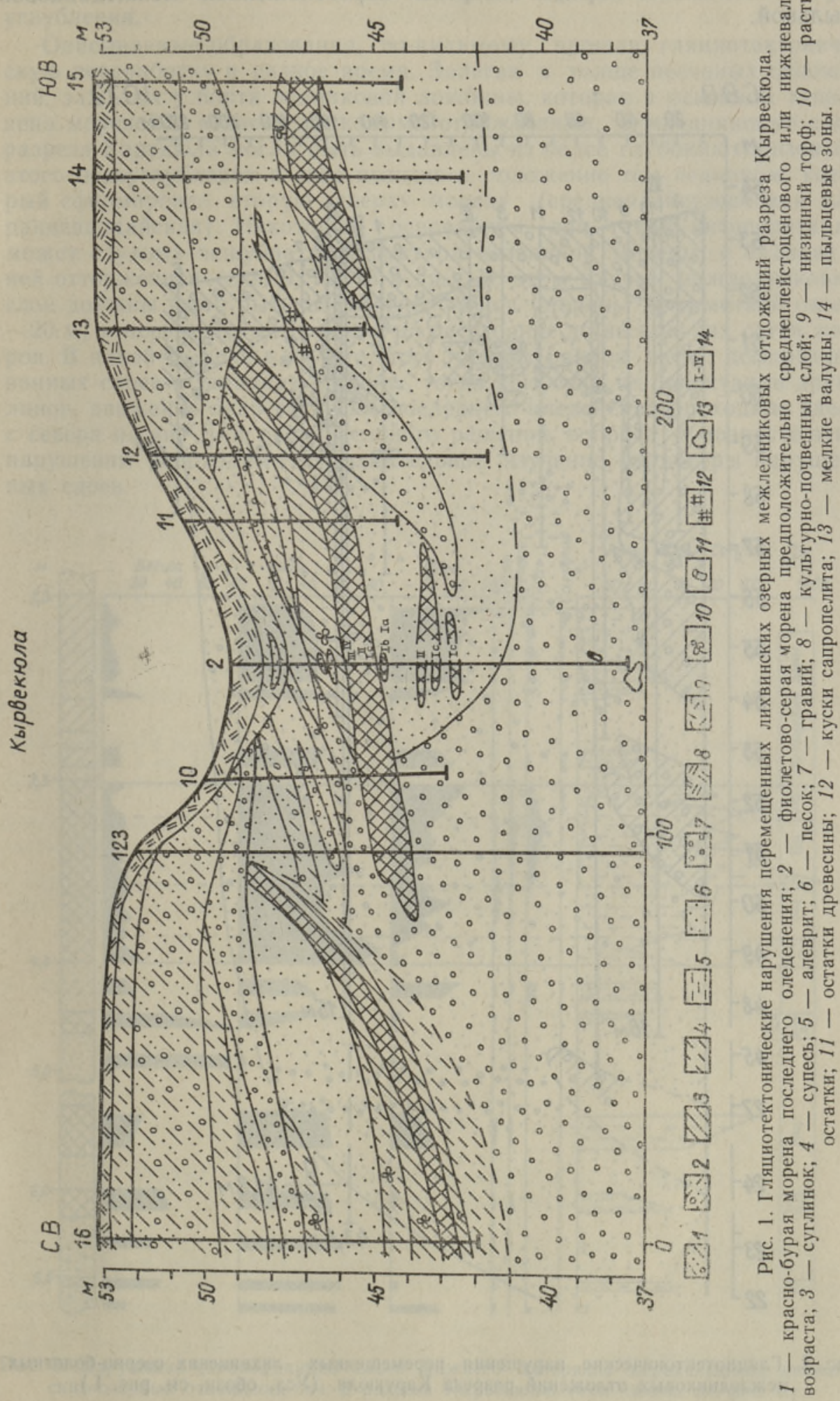


5. В песчаные и песчано-гравийные отложения, подстилающие органогенную толщу в разрезах Кырвекюла (скв. 2) и Карукюла (скв. $1,2,3)$, вкраплены куски тех же межледниковых образований. Да и сами обломочные породы засорены переотложенной межледниковой пыльцой.

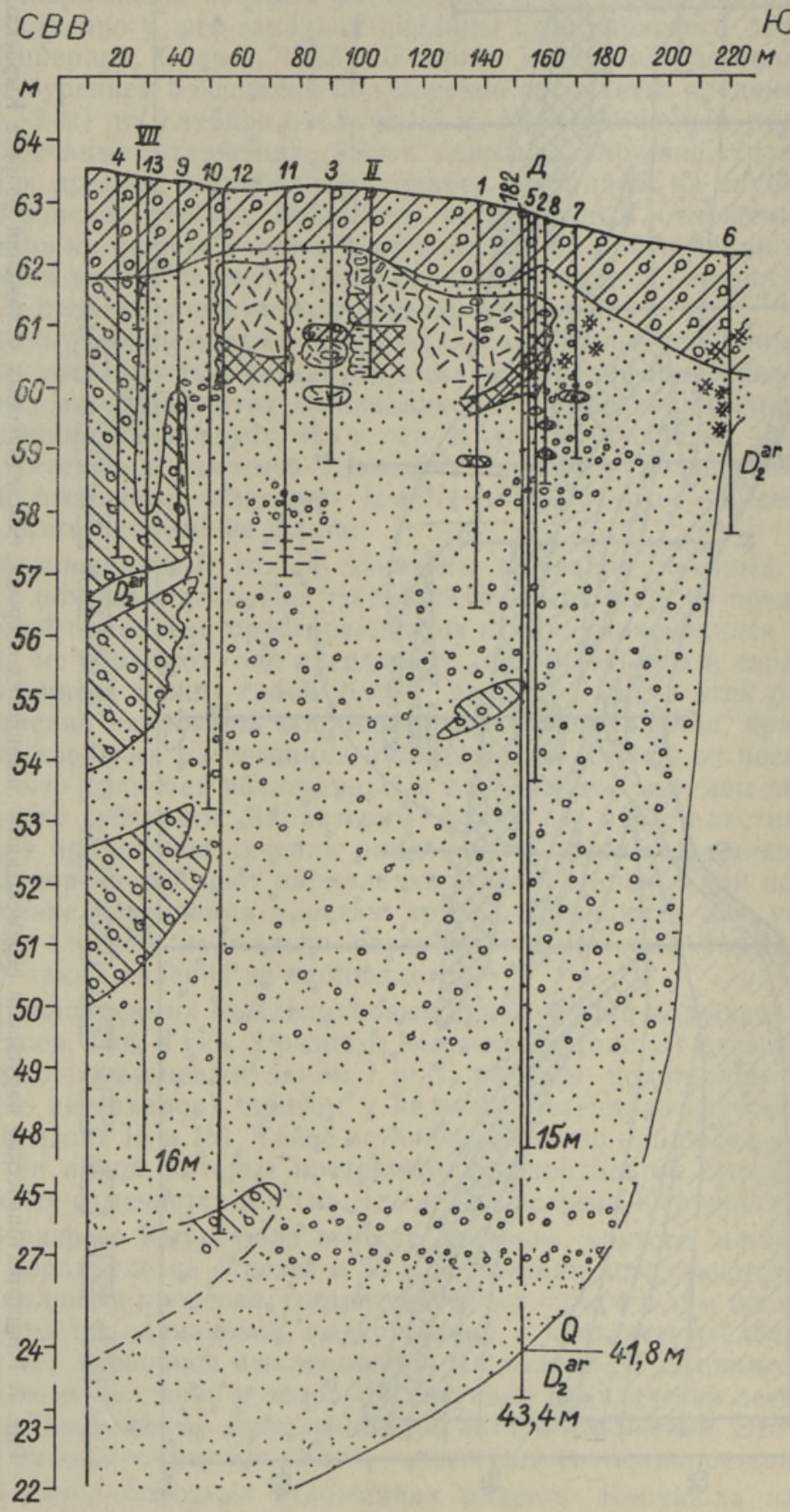

Рнс. 2. Гляциотектонические нарушения перемещенных лихвинских озерно-болотных межледннковых отложений разреза Карукюла, (Усл. обозн, см. рис. 1.) 
Таким образом, совокупность значительной группы признаков дает возможность заключить, что межледниковые отложения в разрезах Карукюла и Кырвекюла имеют не первичное залегание, а перемещены в результате гляцигенного воздействия на породы, заполнявшие переуглубления.

Описываемые образования, по-видимому, прошли гляциотектоническую переработку в разное время. Залегая в толще песчаных отложений, зажатых у борта ледниковой ложбины, которая в основном заполнена мореной и водно-ледниковыми отложениями, межледниковые слои разреза Карукюла могли быть выдавлены из более глубоких горизонтов этого переуглубления в свое нынешнее положение тем ледником, который сформировал вторую сверху морену (среднеплейстоценовая или ранневалдайская). Некоторым основанием для такой интерпретации может служить чешуйчатая структура названной морены и наличие в ней отторженцев (скв. 9, 12, 13 и др.). В этом случае межледниковые слои должны были быть захвачены из-под морены (с отметкой около -20 м) и перемещены к востоку на расстояние до нескольких сотен метров. В какой-то мере в пользу этого говорит наклон части деформированных слоев в западную сторону, тогда как, судя по ориентации друмлинов, движение льда во время последнего оледенения проходило здесь с севера на юг. Для окончательного решения вопроса о возрасте этих нарушений необходимо дополнительное изучение структуры нарушенных слоев.

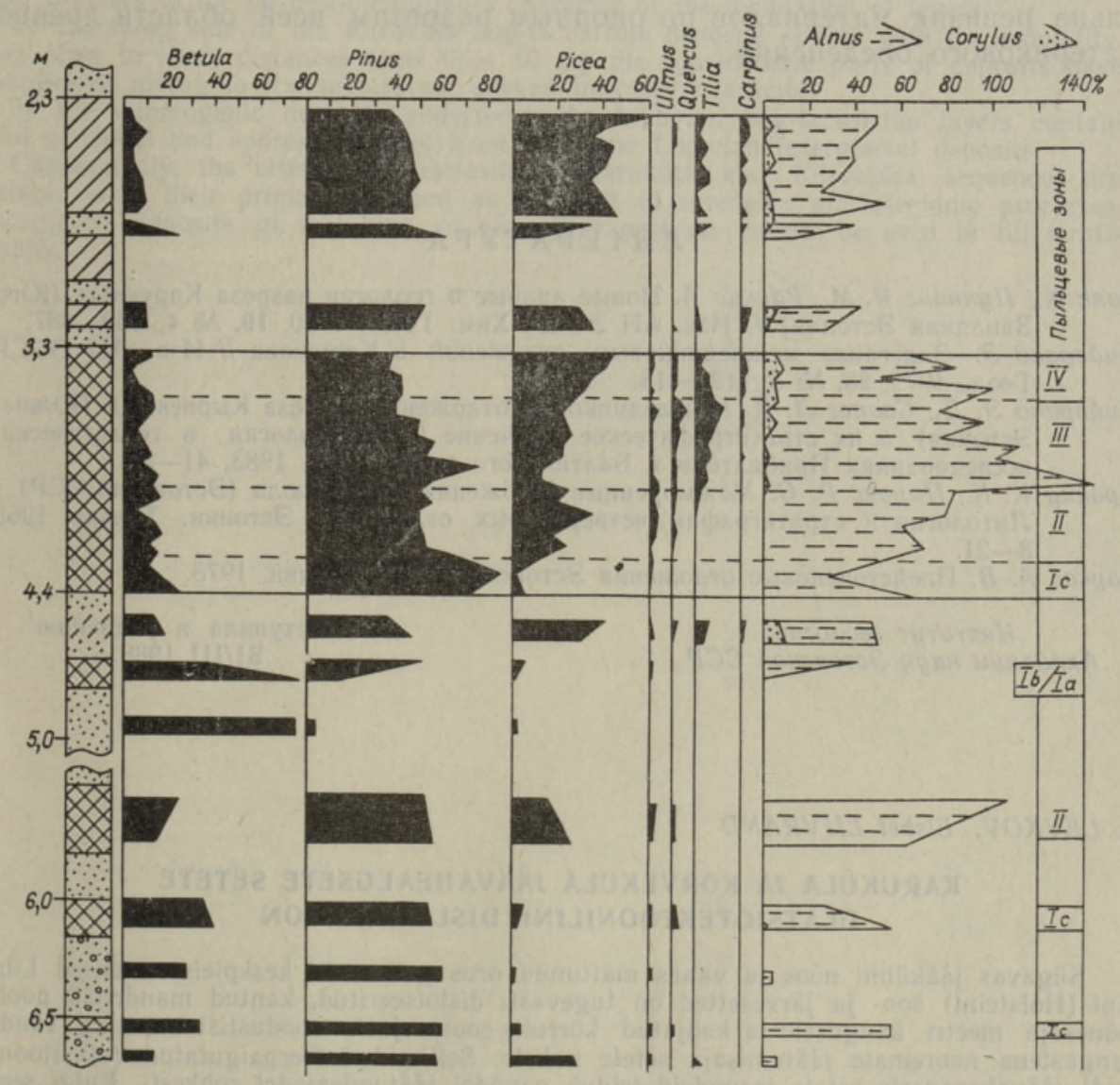

Рис. 3. Нарушение стратификации слоев нижнего интервала перемещенных лихвинских озерных отложений скв. 2 разреза Қырвекюла. (Усл. обозн. см. рис. 1.) 
Более уверенно интерпретируется время разрушения межледниковых образований в разрезе Кырвекюла. В этом месте дислоцированные породы залегают под одной (валдайской) мореной на площади, расположенной непосредственно в зоне бывшего сочленения льдов с разной динамической активностью (активного и пассивного), что скорее всего и предопределило локализацию нарушений. Расположение небольшого понижения в рельефе современной поверхности непосредственно над торцами вовлеченных в перемещение слоев позволяет предположить, что структура дислоцированной толщи и текстура морены формировались одновременно (рис. 1). Перенос блоков межледниковых пород, вероятно, был небольшим (десятки и первые сотни метров) и происходил из места, расположенного между скв. 16 и 125.

Наклон слоев в разрезе Кырвекюла к северо-западу указывает на то, что ледниковый стресс здесь был ориентирован с северо-запада на юговосток. Именно в этом направлении двигался и лед, приведший к появлению расположенного рядом друмлинового поля и образованию дислокаций.

Приведенные данные позволяют сделать вывод о том, что в процессе формирования ледниковых горизонтов многие межморенные интервалы, в первую очередь сложенные торфяниками и другими податливыми ледниковому воздействию породами, могли претерпеть значительную гляциотектоническую перестройку и в таком случае не могут избираться в качестве опорных разрезов при стратиграфических построениях и корреляциях моренных слоев. Вот почему сейчас с названных позиций актуальна ревизия материалов по опорным разрезам всей области древнематерикового оледенения.

\section{Л И ТЕ Р А Т У Р А}

Каяк К., Пуннинг Я.-М., Раукас А. Новые данные о геологии разреза Карукюла (ЮгоЗападная Эстония) // Изв. АН ЭССР. Хим. Геол., 1970, 19, № 4, 350-357.

Лийвранд Э. Залегание межледниковых отложений в Карукюла // Изв. АН ЭССР. Геол., 1979, 28, № 3, 112-118.

Лийвранд Э. Д., Саарсе Л. А. Межледниковые отложения разреза Кырвекюла (Южная Әстония) и их стратиграфическое значение // Палинология в геологических исследованиях Прибалтики и Балтийского моря. Рига, 1983, 41-50.

Орвику K. К., Пиррус Р. О. Межморенные отложения в Карукюла (Эстонская ССР) I/ Литология и стратиграфия четвертичных отложений Эстонии. Таллин, 1965, $3-21$.

Раукас А. В. Плейстоценовые отложения Эстонской ССР. Таллин, 1978.

\author{
Ннститут геологии \\ Академии наук Эстонской ССР
}

\section{Поступила в редакцию} $31 /$ III 1988

\section{E. LEVKOV, Elsbet LIIVRAND}

\section{KARUKULA JA KORVEKULA JÄĂVAHEAEGSETE SETETE GLATSIOTEKTOONILINE DISLOKATSIOON}

Sügavas jääkünni nõos ja vanas mattunud orus paiknevad keskpleistotseensed Lihvini (Holsteini) soo- ja järvesetted on tugevasti dislotseeritud, kantud mandrijää poolt mõnesaja meetri kaugusele ja kuhjatud kurrulis-soomusjate moodustistena ning rändpangastena nooremate jäätumisaja setete vahele. Selliseid ümberpaigutatud (allohtoonseid) jäävaheaegsete setete lasundeid leidub vanadel jäätumisaladel rohkesti. Kuigi seesuguste setete vanuse määramine paleontoloogiliste meetodite abil ei valmista üldiselt raskusi, on nende kasutamine moreenide vanuse hindamisel ja korrelatsioonil ohtlik, sest kihtide esialgne järjestus vōib olla oluliselt rikutud. 


\section{ON GLACIOTECTONICAL DISLOCATIONS OF INTERGLACIAL DEPOSITS IN KARUKOLA AND KORVEKULA SECTIONS \\ (ESTONIA)}

Subdivision of the Pleistocene cover is to a great extent based on the position of interglacial deposits in sequences. Unfortunately they may be considerably destroyed, replaced from their primary position and carried between the younger layers in the ancient glaciated area. Because of that the elucidation of the bedding conditions simultaneously with their age determination is of urgent necessity. In South Estonia clear evidences of glaciotectonical destructions and secondary position of Likhvian (Holsteinian) interglacial deposits have been discovered in Karuküla and Kōrveküla sections, situated in the limits of a glacial ploughing depression and an old buried valley, respectively (Fig. $1-3$ ). That is confirmed by the following facts:

1) Interglacial deposits do not form strictly extended and gradually wegded out layers, characteristic to the Holocene ones. They are represented by interrupted, fragmentary and unconnected blocks of sediments. As a result of ice push the flaky textures have been formed, which in longitudinal section are inclined in the proximal direction of ice pressure. Termination of layers is very sharp without diminishing in thickness.

2) The stratification of layers in blocks has been destroyed and splitted. For instance, pollen zones I and II occur twice in the sequence (Fig. 3). In addition, the lower part of the block has lost its base. The same events are traceable in Karuküla section. Destructions of that kind are caused by horizontal displacement of interglacial boglacustrine deposits.

3) Within a short distance $(36 \mathrm{~m})$ the inclination of interglacial sapropelite in Korrveküla section is very steep $(2 \mathrm{~m})$. However, the thickness of the layers corresponding to certain pollen zones remains unchangeable, without any traces of wedging out. With similar conditions in present sedimentation basins the facial differences occur in any case. It refers to the postsedimentational character of the inclination of layers.

4) The lying side of the Karuküla bog-lacustrine deposits strikes with its instability. Very often in short distances (less than $10 \mathrm{~m}$ ) the considerable parts of deposits have disappeared giving to the substratum uneven indented character.

5) The minerogenic deposits underlying the Likhvian bog-lacustrine layers contain a lot of pollen and spores rebedded from the same Likhvian interglacial deposits.

Consequently, the interglacial deposits in Karuküla and Kõrveküla sequences are replaced from their primary position as a result of intensive glaciotectonic processes. Interglacial deposits of that kind of secondary position cannot be used in till stratigraphy. 